\title{
Analisa Tingkat Usability Software Open Source ICA-AtoM
}

\author{
Ach. Nizam Rifqi, S.I.I.P. \\ Perpustakaan Politeknik Negeri Malang \\ (nizamrifqi@gmail.com)
}

\begin{abstract}
INTISARI
Penelitian ini membahas dan mengkaji mengenai seberapa tingkat usability salah satu software bidang arsip digital dengan berbasis opensource yaitu ICA-AtoM. Latar belakang penulisan adalah dengan perkembangan teknologi informasi yang sudah menjadi bagian tak terpisahkan dalam kehidupan masyarakat, khususnya dalam dunia informasi dan dokumentasi dunia kearsipan bahwa penggunaan teknologi informasi cukup intens dilakukan. Pada perkembangannya muncul berbagai software yang cukup berkompeten dalam pengelolaan arsip berbasis digital, terlebih sekarang ini telah banyak software dengan berbasis opensource yang salah satunya adalah ICA-AtoM. Secara metodologi analisa tingkat Usability dilakukan pada ICA-AtoM versi 1.3.1 melalui metode checklist dengan mengacu pada point-point indikator usability yang dikemukakan oleh Nielsen. Hasil analisa menunjukkan bahwa tingkat usability software ICA-AtoM diperoleh hasil prosentase 56,7\% yang artinya masih sepatuh dari ketercapaian usability. Analisa menunjukkan aspek usability terendah terdapat pada point Error prevention (Pencegahan Kesalahan) dan Recognition rather than recall (Mengenali bukan Mengingat) di mana masing-masing aspek diperoleh nilai $0 \%$ yang artinya kedua aspek tersebut sama sekali belum terpenuhi. Sedangkan hasil tertinggi diperoleh pada aspek Flexibility and efficiency of use (Fleksibilitas dan Efisiensi Penggunaan) dan Aesthetic and minimalist design (Estetika \& desain yang minimalis) yang masing-masing diperoleh hasil prosentase $100 \%$.
\end{abstract}

Kata Kunci: arsip Digital, ICA-AtoM, software open source, usability.

\section{ABSTRACT}

This research discusses and examines about the usefulness of one of the software with the opensource archive ICA-AtoM. The background of writing is with the development of information technology that has become an integral part of people's lives, especially in the world of information and documentation of the world of archiving the use of information technology is quite intense. In its development appeared a variety of software that is quite competent in the management of digital-based archive, especially now has a lot of software with opensource-based one of which is ICA-AtoM. Methodology Usability level analysis is performed on ICA-AtoM version 1.3.1 checlist method with point value indicator clarity indicated by Nielsen. The result of analysis shows that the level of usability of ICA-AtoM software obtained result of percentage 56,7\% which means still fall from usability achievement. The analysis shows that the lowest usability aspect is in the Error prevention and Recognition rather than recall points where each aspect is $0 \%$, which means that the two aspects are completely unfulfilled. While the highest results obtained on the aspect of Flexibility and efficiency of use and Aesthetic and minimalist design (each aesthetic 100\%).

Keywords: digital archive, ICA-AtoM, open source software, usability. 


\section{PENGANTAR}

\section{Latar Belakang Masalah}

Teknologi informasi telah menjadi bagian yang tidak terpisahkan dari kehidupan global. Pesatnya penggunaan teknologi informasi ini juga diperkuat dengan pernyataan Kementerian Komunikasi dan Informatika (Kemkominfo) bahwa pengguna internet di Indonesia hingga saat ini telah mencapai 82 juta orang dan berada pada peringkat ke- 8 di dunia (Kominfo, 2017). Berdasarkan hal tersebut dapat dilakukan penafsiran bahwa dengan capaian itu Indonesia berada pada peringkat ke- 8 di dunia .

Beberapa kegiatan pun seiring dengan perkembangan teknologi informasi kian meningkat. Fakta menunjukkan lebih dari satu dasawarsa lalu, bahwa di Amerika setiap tahunnya pihak pemerintah membuat laporan yang ditaksir mencapai 100.000 laporan, ditambah 450.000 artikel, buku dan laporan yang sama-sama terbit. Berdasar hasil tersebut jika diperhitungkan seluruh dunia tingkat penerbitannya setiap tahun dapat mencapai 60 juta halaman (Toffler, 1980). Perlu dicatat bahwa hasil tersebut merupakan hasil dari lebih satu dasawarsa lalu, secara otomatis bahwa pada era sekarang ini jumlah tersebut sudah terlampaui amat jauh. Oleh karena itu, setiap institusi, berlomba untuk mengintegrasikan teknologi informasi guna membangun dan memberdayakan sumber daya manusia berbasis pengetahuan agar dapat bersaing di era global.
Tidak dapat dipungkiri seiring dengan perkembangan teknologi informasi, kaitannya dengan proses dokumentasi menjadi sesuatu yang sangat vital guna menjaga rekam berbagai kegiatan tersebut, baik itu dalam ruang lingkup pemerintahan, perdagangan ataupun dunia akademis pendidikan. Hal tersebut dikarenakan informasi yang menjadi suatu komoditi dalam setiap kegiatan merupakan kebutuhan yang mendasar. Salah satu sumber informasi adalah rekaman data-data dalam berbagai media yang disebut arsip. Mengingat pentingnya peran arsip dalam mendukung aktifitas, maka perlu dilakukan pengelolaan arsip secara baik dengan bantuan teknologi informasi atau dapat disebut sistem manajemen arsip.

Adanya sistem manajemen kearsipan yang efektif, akan dapat menyediakan data dan informasi dengan cepat dan tepat. Hal tersebut juga sebagaimana diungkapkan oleh Edgar Crook dalam tulisannya yang berjudul "Web Archiving in a Web 2.0 Word" dikemukakan bahwa penggunaan teknologi informasi dalam bidang kearsipan juga memiliki manfaat pertama kita tidak perlu menghawatrkan masalah tempat, dapat melakukan pengendalian konten yang terkumpul serta tampilan halaman sesuai kebutuhan atau dengan katalain memudahkan di dalam manajemen kontrol (Crook, 2009:833).

Sekitar satu dekade ini di Indonesia telah banyak bermunculan software khususnya bidang kearsipan yang cukup concern terhadap sistem informasi dan pengelolaan dokumen arsip. 
Beberapa software dikembangkan dengan menyediakan berbagai fitur modul baik itu modul di dalam pengelolaan maupun dalam segi interface serta fitur penelusuran dengan menggunakan open source atau primary software. Software yang berbais open source mengalami perkembangan yang cukup pesat. Hal tersebut dapat dilihat dengan menjamurnya komunitas - komunitas peminat dan pengembang beberapa software open source.

ICA-AtoM (International Council on Archives Access to Memory) merupakan salah satu software pengelolaan arsip dengan berbasis manajemen yang bersifat open source. ICAAtoM dalam pembuatannya merupakan software berbasis web yang secara operasional menggunakan web browser seperti Firefox, Internet Exploler, Opera. Keberadaanya ditujukan sebagai sebuah aplikasi untuk mendeskripsikan arsip dengan berbagai bahasa, serta dalam pengembangannya sebagai tempat penyimpanan arsip (multi repository). Software tersebut dikatakan cukup populer. Hal ini dapat dilihat dari perkembangan tahun ke tahun software tersebut memiliki tim pengembang yang baik pada masalah fitur maupun segi tampilan (interface). Perkembangan terbaru saat ini yaitu ICA-AtoM versi 1.3.1.

Beberapa studi mengenai analisa penerapan ICA-AtoM pernah dilakukan. Salah satunya mengenai Pengujian Ketepatan dan Perolehan Aplikasi ICA-AtoM sebagai Sarana Temu Kembali Arsip di Universitas Indonesia yang dilakukan oleh Agit Grahito tahun 2014.
Hasil penelitiannya menunjukkan bahwa ICAAtoM dalam penerapannya sebagai sarana temu kembali dapat dikatakan sangat baik dengan diperoleh hasil ketepatan (precision) sebesar $88,6 \%$ dan perolehan (recall) sebesar 90,5\%. Namun disisi lain belum diketahui secara pasti mengenai seperti apa karakteristik kemudahankemudahan (usability) yang diberikan oleh ICAAtoM khususnya untuk versi yang 1.3.1, sehingga nanti kedepannya dapat dilakukan pengembangan mengenai fitur-fitur dan fasilitas apa yang perlu ditambahakan dalam tahap pengembangan.

Berangkat dari fenomena tersebut maka penulis ingin melakukan suatu analisis yang jauh lebih dalam mengenai analisa tingkat usability software berbasis open source ICA-AtoM versi 1.3.1. Hal tersebut dilakukan dengan dasar pertimbangan masih minimnya kajian - kajian terkait software dibidang kearsipan khususnya yang berkaitan dengan fasilitas dan fitur di dalamnya, sehingga dengan diketahui hasil dari analisa tersebut dapat dilakukan pemetaan guna pengembangan lebih lanjut terkait software dalam bidang kearsipan.

\section{Landasan Teoritis}

\section{Konsep Arsip Digital}

Sebelum membahas lebih mendalam mengenai arsip, maka pertama harus diketahui terlebih dahulu mengenai pemahaman awal apa itu arsip. Menurut Undang-Undang No. 43 Tahun 2009, yang dimaksud dengan arsip secara garis besar adalah rekaman kegiatan 
yang dibuat dan diterima oleh lembaga negara, pemerintahan daerah, lembaga pendidikan, perusahaan, organisasi politik, organisasi kemasyarakatan, dan perseorangan dalam bentuk corak apapun baik dalam keadaan tunggal maupun berkelompok dalam rangka pelaksanaan kegiatan pemerintahan yang terdiri dari arsip dinamis, vital, aktif, inaktif, statis, terjaga, dan umum. Selain itu arsip juga dapat diartikan sebagai suatu badan (agency) yang melakukan segala kegiatan pencatatan penanganan, penyimpanan dan pemeliharaan suratsurat/warkat-warkat yang mempunyai arti penting baik ke dalam maupun ke luar, baik yang menyangkut soal-soal pemerintahan maupun non pemerintahan dengan menerapkan kebijaksanaan dan sistem tertentu yang dapat dipertanggungjawabkan (Bartos, 2005: 2). Berdasar pada pengertian di atas dapat diambil suatu kesimpulan bahwa arsip pada hakikatnya merupakan suatu bentuk rekaman kegiatan atau peristiwa dalam berbagai bentuk ataupun media seiring dengan perkembangan teknologi informasi dan komunikasi yang dibuat dan diterima oleh lembaga negara, pemerintahan daerah lembaga pendidikan perusahaan dan lain sebagainya.

Perkembangan teknologi yang terjadi sebagaimana diketahui dalam implementasinya arsip tidak hanya terbatas pada penyimpanan media cetak, tetapi juga dilakukan melalui media elektronik. Arsip yang dahulunya memiliki bentuk cetak kini banyak yang bertransformasi dalam bentuk digital. Hal ini menjadi pendorong munculnya konsep arsip elektronik atau arsip digital.
Secara konsep, arsip digital merupakan objek atau informasi digital, obyek atau informasi digital tersebut tersimpan dalam sebuah simpanan kelembagaan dengan tujuan agar informasi tersebut dapat diakses oleh masyarakat sampai kapanpun. Dengan demikian, dapat dikatakan bahwa arsip digital merupakan sebuah simpanan kelembagaan yang menyimpanan satu atau lebih obyek informasi digital. Hal ini bertujuan menyimpan arsip dalam waktu yang relatif lama dan dapat diakses informasinya melalui sebuah wadah atau yang disebut dengan istilah repository. Tujuan dari penyimpanan tersebut tidak lain adalah agar informasi dapat diakses oleh masyarakat kapanpun dan dimanapun.

\section{Pengelolaan Sistem Kearsipan Digital}

Perkembangan arsip digital di seluruh dunia telah menyebar ke universitas atau pergururan tinggi serta institusi pemerintah nasional dan internasional. Awal kemunculan arsip digital dalam ruang lingkup tersebut dikaji oleh pengembangan akar rumput dari gudang digital pribadi, departemen dan interdisipliner. Di balik pertumbuhan itu, dalam konteks dunia akademis universitas dan perguruan tinggi, gelombang pasang dokumen digital yang dihasilkan oleh fakultas dan mahasiswa, serta kebutuhan untuk membuat dokumen-dokumen ini lebih banyak tersedia (Falk, 2003:375). 
Proses pengolahan arsip dalam konteks arsip digital merupakan lembaran-lembaran arsip yang telah dilakukan proses konversi dari yang sebelumnya dalam bentuk cetak menjadi bentuk file gambar dengan format "jpg", "png", "bmp" atau dokumen dengan format "doc", "txt" dan lain sebagainya. Hal ini mengingat bahwa prinsip pengelolaan arsip digital teknologi informasi seperti komputer dan software didalamnya berperan sebagai fasilitator pengelolaan.

Secara konsep sistem pengelolaan arsip digital dengan konvensional dapat dikatakan sama (Sugiarto \& Teguh Wahyono, 2005: 137).
Perbedaan antara kedua hal tersebut dapat dilihat dari jenis media/komponen yang digunakan dalam pengelolaan arsip. Jika pada sistem kearsipan konvensional memiliki kabinet yang secara fisik berfungsi untuk menyimpan dokumen-dokumen penting yang dimiliki oleh suatu instansi, maka dalam sistem kearsipan digital memiliki kabiner virtual yang di dalamnya berisi map virtual. Berikut ditunjukkan mengenai perbedaan media/ komponen yang dipergunakan antara sistem kearsipan konvensional dengan sistem kearsipan digital berdasarkan konsep Sugiarto \& Teguh Wahyono (2005: 138).

Tabel 1

Perbedaan Komponen Sistem Kearsipan

Konvensional dan Modern/Digital

\begin{tabular}{|l|l|l|l|}
\hline No. & \multicolumn{1}{|c|}{ Komponen } & \multicolumn{1}{|c|}{ Kearsipan Konvensional } & \multicolumn{1}{c|}{$\begin{array}{c}\text { Kearsipan } \\
\text { Modern/Digital }\end{array}$} \\
\hline 1. & Kabinet & $\begin{array}{l}\text { Berupa rak atau lembar arsip yang } \\
\text { dibuat secara fisik. }\end{array}$ & $\begin{array}{l}\text { Berupa kabiner virtual } \\
\text { yang dibuat dengan } \\
\text { databse. }\end{array}$ \\
\hline 2. & Map & $\begin{array}{l}\text { Berupa map fisik untuk menyimpan } \\
\text { lembaran arsip. }\end{array}$ & $\begin{array}{l}\text { Berupa map virtual } \\
\text { atau folder untuk } \\
\text { menyimpan file } \\
\text { dokumen. }\end{array}$ \\
\hline 3. & Arsip & Lembaran-lembaran surat hard copy. & $\begin{array}{l}\text { Lembaran- } \\
\text { lembaransurat yang } \\
\text { sudah di transfer ke } \\
\text { dalam file gambar/teks. }\end{array}$ \\
\hline
\end{tabular}




\section{Software Opensource Archival ICA-AtoM}

Sebagaimana diketahui dalam perkembangannya banyak bermunculan beberapa software yang berkaitan dengan dunia kearsipan yang berbasis open source. ICA-AtoM dapat dikatakan satu dari beberapa software open source yang cukup populer yang terus melakukan pengembangan.

ICA-AtoM adalah singkatan dari "International Council on Archives Access to Memory". Karakteristik software adalah berbasis open source, perangkat lunak deskripsi arsip berbasis web yang bertujuan memudahkan arsip untuk menyediakan akses secara online ke kepemilikan arsip mereka. Secara perangkat ICA-AtoM telah memenuhi standart ICA serta dalam penerapannya mendukung banyak jenis koleksi melalui perangkat lunak yang fleksibel sehingga dikatakan ICA-AtoM merupakan software multi repository (Sipro, 2009: 26).

Aplikasi ini sedang dikembangkan secara aktif oleh ICA dengan melakukan beta testing. Aplikasi ini dapat diakses secara online melalui www.ica-atom.org yang merupakan halaman awal dari projek ICA-AtoM. ICA-AtoM juga menyediakan online demo bagi praktisi kearsipan untuk mencobanya langsung melalui www.ica-atom.org/demo, disini arsiparis dapat masuk dan mencoba fitur yang ada dengan menjadi admin pada demo secara online. Fitur dari ICA-AtoM secara teknis dirancang untuk mendukung agregasi data dari beberapa institusi melalui OAI, IETF Atom Publishing Protocol (APP), dan kemungkinan mekanisme lainnya. Pengembang sedang mengerjakan Pilot project dengan Archives Association of British Columbia untuk membangun sebuah portal daftar agregat gabungan. ICA-AtoM bertujuan untuk membedakan dirinya melalui dukungan untuk translasi dan internasionalisasi, basis di Indonesia Standar ICA seperti ISAD-G dan ISAD-H, fleksibilitas Dan customizability, dan kemudahan pemasangan dan penggunaan.

ICA-AToM sebagai aplikasi berbasis web, sepenuhnya bisa diakses dari manapun dengan koneksi internet dan bisa di-host dengan biaya minimal dalam jangka panjang. Para pengembang menginginkan ICA-AToM menjadi platform untuk mengelola informasi arsip, termasuk membuat interface repository digital untuk sistem seperti Dspace dan Fedora melalui arsitektur plug-in. Mereka merencanakan untuk membangun fitur Web 2.0 seperti kontribusi pengguna konten, penandaan pengguna, dan jejaring sosial. Berikut merupakan tampilan awal software ICA-AtoM versi 1.3.1: 

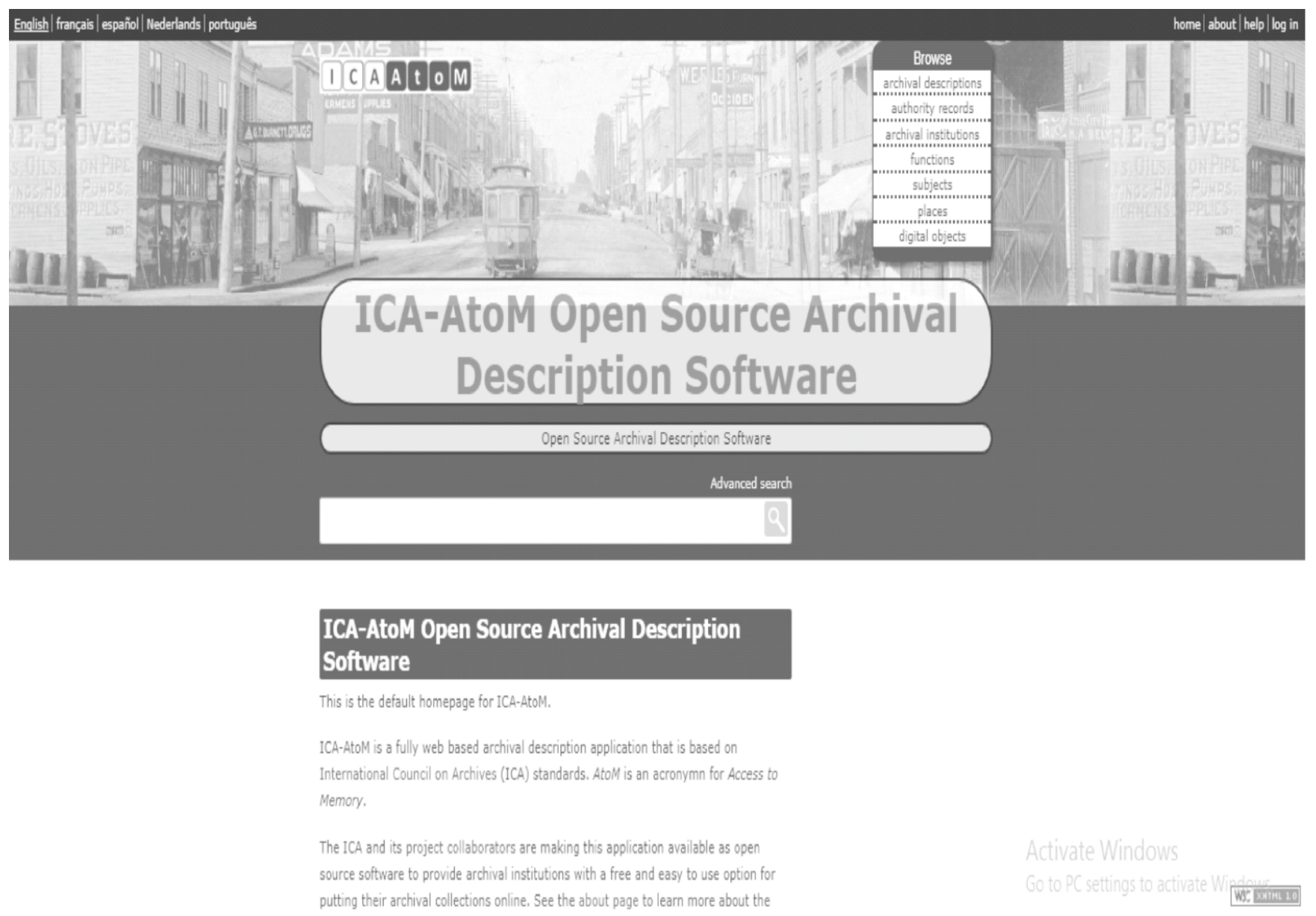

Gambar 1

Halaman Utama ICA-AtoM versi 1.3.1

\section{Konsep Uji Usability}

Secara umum kriteria yang menentukan bahwa sebuah software (memiliki tingkat usability yang tinggi) yang dalam konteks ini software tersebut berbentuk aplikasi yang berbasis website, apabila pengguna bisa menemukan atau memperoleh apa yang mereka butuhkan dan mengerti fungsi-fungsi dari software tersebut. Menurut Nielsen (1994), terdapat sepuluh usability heuristics untuk user interface design kaitannya dengan tampilan sebuah website atau aplikasi yang dijabarkan Nielsen \& Molich (1994) sebagai berikut: 
a. Visibility of system status. (Visibilitas status sistem informasi) dalam pembahasan kali ini, sistem harus selalu menjaga informasi kepada pengguna melalui isyarat visual untuk membantu pengguna ketika mengakses sebuah aplikasi dan untuk mengidentifikasi apakah tindakan yang dilakukan pengguna dalam sebuah aplikasi itu benar atau tidak;

b. Match between system and the real world (kesesuaian antara sistem dan dunia nyata), yaitu bahasa yang digunakan pada sistem aplikasi menggunakan kata-kata, konsep kalimat atau konsep bahasa yang dapat dipahami oleh pengguna;

c. User control and freedom (Kontrol dan Kebebasan Pengguna): Heuristik ini difokuskan untuk dapat memudahkan pengguna ketika mengakses baik Omeka maupun ICA-AtoM;

d. Consistency and standards (Standard dan Konsistensi): Kekonsistensian itu misalnya adalah pada tampilan yang dibuat hingga pada konten yang ditampilkan;

e. Error prevention. (Pencegahan Kesalahan): Poin heuristik ini dimaksudkan untuk melakukan langkah pencegahan terhadap adanya kemungkinan terjadinya suatu kesalahan dalam sebuah website;

f. Recognition rather than recall (Mengenali bukan Mengingat): Poin heuristik keenam ini yakni mengenai instruksi atau petunjuk untuk cara penggunaan sebuah fitur dalam suatu aplikasi;

g. Flexibility and efficiency of use. (Fleksibilitas dan Efisiensi Penggunaan): Poin heuristik ini menjelaskan mengenai fleksibilitas dan efisiensi sebuah aplikasi; h. Aesthetic and minimalist design. (Estetika \& desain yang minimalis): Poin heuristik kedelapan ini lebih menjelaskan mengenai urusan desain interface dari aplikasi, dan desain interface pada aplikasi diharapkan minimalis namun tidak monoton dengan asumsi membuat pengguna nyaman melihatnya;

i. Help users recognize, diagnose, and recover from errors (Membantu pengguna untuk mengenali, mendiagnosa, memulihkan dari kesalahan): Poin heuristik selanjutnya yakni lebih membahas mengenai adanya error messaging atau pesan kesalahan; dan

j. Help and documentation (Bantuan dan dokumentasi): Heuristik poin yang terakhir ini lebih mengulas mengenai adanya bantuan dan dokumentasi yang dimiliki oleh suatu aplikasi.

\section{Metodologi}

Jenis penelitian yang digunakan adalah kuantitatif deskriptif. Analisa dilakukan melalui metode checklist. Checklist dalam hal ini berfungsi sebagai indentifikasi terhadap fiturfitur yang dimiliki oleh ICA-A toM versi 1.3.1 dengan berdasar pada standar penilaian usability yang dikemukakan oleh Nielsen (1994). Format analisa checklist menggunakan setiap butir indikator dalam penilaian usability yang terdiri dari 10 point indikator yang kemudian dijabarkan secara operasional oleh peneliti menjadi 20 butir item. Setiap indikator yang sesuai akan diberikan tanda (V) sedangkan yang tidak sesuai diberikan tanda $(0)$. 
PEMBAHASAN

Analisa Tingkat Usability Omeka dan ICAAtoM
Analisa dilakukan dengan mengelompokkan data checlist sesuai dengan konsep uji usability Nielsen (1994) yang terdiri dari 10 poin indikator sebagai berikut:

\section{Visibilitas Status Sistem Informasi}

Tabel 2

Indikator Visibilitas Status Sistem informasi

\begin{tabular}{|c|c|c|}
\hline No. & Butir Checklist & $\begin{array}{l}\text { ICA- } \\
\text { AtoM }\end{array}$ \\
\hline 1. & $\begin{array}{l}\text { Terdapat indikator yang menunjukkan proses loading pada } \\
\text { sistem. }\end{array}$ & 0 \\
\hline 2. & $\begin{array}{l}\text { Menampilkan suatu pemberitahuan kata sandi yang } \\
\text { dimasukkan ketika proses registrasi sistem (lemah, sedang, } \\
\text { kuat). }\end{array}$ & $\mathrm{v}$ \\
\hline \multirow[t]{3}{*}{3.} & $\begin{array}{l}\text { Tampilan sebagai pengingat agar tidak terjadi kesalahan dalam } \\
\text { input data. }\end{array}$ & 0 \\
\hline & Skor & 1 \\
\hline & Prosentase & $33,3 \%$ \\
\hline
\end{tabular}

Sumber: Data Primer

Hasil checklist mengenai visibilitas status sistem informasi terkait dengan ICAAtoM didapatkan hasil prosentase 33,3\%. Data ini menunjukkan terdapat 2 poin yang belum terpenuhi yaitu masih belum terdapat indikator yang menunjukkan bahwa ketika pengguna melakukan suatu fungsi dalam ICA-AtoM selalu menampilkan proses loading. Poin kedua belum terdapat suatu tampilan sebagai tanda pengingat dalam melakukan kegiatan pada sistem. Hal ini dapat dicontohkan ketika pengguna mendapatkan pesan saat memasukan kode sandi pada form pendaftaran dalam proses regsitrasi instalasi ICA-AtoM. 


\section{Kesesuaian antara Sistem dan Dunia Nyata}

Tabel 3

Indikator Kesesuaian antara Sistem dan Dunia Nyata

\begin{tabular}{|l|l|c|}
\hline No. & \multicolumn{1}{|c|}{ Butir Checklist } & ICA-AtoM \\
\hline 1. & Pengorganisasian dilakukan secara terstruktur dalam sistem. & 0 \\
\hline 2. & Bahasa yang digunakan bersifat umum dan mudah dimengerti. & v \\
\hline 3. & $\begin{array}{l}\text { Terdapat pesan ketika terjadi eror dengan bahasa yang mudah } \\
\text { dipahami. }\end{array}$ & V \\
\hline 4. & Terdapat pilihan bahasa sesuai kebutuhan. & 0 \\
\hline & Skor & 2 \\
\hline & Prosentase & $50 \%$ \\
\hline
\end{tabular}

Sumber: Data Primer

Aspek kesesuaian antara sistem dan dunia nyata berdasarkan hasil checklist diperoleh hasil prosestase $50 \%$ yang artinya separuh dari poin indikator aspek tersebut telah terpenuhi, yaitu 2 dari 4 poin indikator. Data menunjukkan bahwa pada ICA-AtoM masih belum melakukan pengorganisasian secara terstruktur dalam sistem. Hal ini dapat dilihat dari halaman sistem khususnya menu yang disediakan masih kurang terpusat pada satu lokasi, sehingga tampilan informasi menu terkesan kurang fokus. Mengenai bahasa masih belum terpenuhi sesuai kebutuan dalam konteks bahasa Indonesia, hal ini sesuai apabila software diterapkan. Sehingga bagi pengguna yang dapat dikatakan masih awam nantinya akan dapat kesulitan dengan masalah bahasa tersebut. 


\section{Kontrol dan Kebebasan Pengguna}

Tabel 4

Indikator Kontrol dan Kebebasan Pengguna

\begin{tabular}{|l|l|c|}
\hline No. & \multicolumn{1}{|c|}{ Butir Checklist } & ICA-AtoM \\
\hline 1. & Terdapat tombol navigasi yang mudah dipahami pada sistem. & 0 \\
\hline 2. & $\begin{array}{l}\text { Terdapat kemudahan dalam penggunaan tombol navigasi pada } \\
\text { sistem. }\end{array}$ & $\mathrm{V}$ \\
\hline & Skor & 2 \\
\hline & Prosentase & $50 \%$ \\
\hline
\end{tabular}

Sumber: Data Primer

Aspek kontrol dan kebebasan pengguna dalam software ICA-AtoM menunjukkan hasil prosentase $50 \%$, dari 2 poin checklist pada tabel tersebut dapat diketahui masih belum terpenuhinya tombol navigasi yang mudah dipahami dalam sistem. Hal ini berhubungan dengan belum fokusnya pengorganisasian informasi dan menu yang disediakan dalam ICAAtom. Halaman dan menu tersebut masih terkesan menyebar, bukan terpusat dan terfokus pada lokasi tertentu, sehingga pengguna dalam melakukan akses menu dapat termudahkan.

\section{Standard dan Konsistensi}

Tabel 5

Indikator Standard dan Konsistensi

\begin{tabular}{|l|l|c|}
\hline No. & \multicolumn{1}{|c|}{ Butir Checklist } & ICA-AtoM \\
\hline 1. & Konsistensi tampilan halaman pada sistem. & V \\
\hline 2. & Konsistensi tataletak menu di sistem. & V \\
\hline 3. & Field input data sesuai dengan standart baku & V \\
\hline & Skor & 3 \\
\hline & Prosentase & $100 \%$ \\
\hline
\end{tabular}

Sumber: Data Primer 
Aspek konsistensi dalam analisa tingkat usability diperoleh hasil yang memuaskan. Terpenuhinya aspek standard dan konsistensi dengan prosentase $100 \%$ dari 3 poin indikator. Desain fitur interface baik dari halaman utama maupun dashboard untuk software ICA-AtoM dikatakan cukup konsisten karena halamanhalaman tersebut memiliki tampilan yang sama. Setiap halaman berbeda, perbedaannya terletak pada penempatan dan fasilitas tombol navigasi yang disediakan.

\section{Pencegahan Kesalahan}

Tabel 6

Indikator Pencegahan Kesalahan

\begin{tabular}{|l|l|c|}
\hline No. & \multicolumn{1}{|c|}{ Butir Checklist } & ICA-AtoM \\
\hline 1. & $\begin{array}{l}\text { Terdapat firut pengingat agar tidak terjadi kesalahan (login, input } \\
\text { dan lain sebagainya). }\end{array}$ & 0 \\
\hline & Skor & 0 \\
\hline & Prosentase & $0 \%$ \\
\hline
\end{tabular}

Sumber: Data Primer

Analisa untuk poin aspek pencegahan kesalahan diperoleh hasil yang kurang memuaskan yaitu $0 \%$ dari sejumlah indikator analisa checklist. Software ICA-AtoM masih perlu dilakukan pengembangan fitur sebagai menu navigasi pengingat jika terjadi suatu kesalahan dalam aktivitas penggunaan sistem.

\section{Mengenali Bukan Mengingat}

Tabel 7

Indikator Mengenali Bukan Mengingat

\begin{tabular}{|l|l|c|}
\hline No. & \multicolumn{1}{|c|}{ Butir Checklist } & \multicolumn{1}{|c|}{ ICA-AtoM } \\
\hline 1. & $\begin{array}{l}\text { Terdapat indikator yang menunjukkan benar atau tidaknya } \\
\text { keyword yang dimasukkan. }\end{array}$ & 0 \\
\hline 2. & $\begin{array}{l}\text { Simbol atau icon digunakan sebagai menu dan fitur aplikasi } \\
\text { sistem. }\end{array}$ & 0 \\
\hline & Skor & 0 \\
\hline & Prosentase & $0 \%$ \\
\hline
\end{tabular}

Sumber: Data Primer 
Mengenali bukan mengingat dalam konteks analisa usability ini merupakan aspek mengenai instruksi atau petunjuk untuk cara penggunaan sebuah fitur dalam suatu aplikasi. Poin untuk aspek ini masih belum terpenuhi di dalam software ICA-AtoM, padahal disisi lain aspek tersebut diperlukan dan diharapkan dapat memberikan kemudahan kepada pengguna dalam mengoperasikan aplikasi.

\section{Fleksibilitas dan Efisiensi Penggunaan}

Tabel 8

Indikator Fleksibilitas dan Efisiensi Penggunaan

\begin{tabular}{|l|l|c|}
\hline No. & \multicolumn{1}{|c|}{ Butir Checklist } & ICA-AtoM \\
\hline 1. & Terdapat menu penelusuran sederhana dalam sistem. & V \\
\hline 2. & Adanya fitur advanced search dalam sistem. & V \\
\hline & Skor & 2 \\
\hline & Prosentase & $100 \%$ \\
\hline
\end{tabular}

Sumber: Data Primer

Software ICA-AtoM dapat dikatakan dengan poin pada aspek ini secara keseluruhan poin fleksibilitas dalam analisa tingkat usability dapat terpenuhi oleh software ICA-A toM. Menu memiliki nilai yang cukup tinggi yaitu dengan prosentase $100 \%$. Hal tersebut dapat dilihat berdasarkan pada hasil analisa checklist sesuai penelusuran yang disediakan juga cukup lengkap sesuai dengan kebutuhan dasar didalam proses penelusuran informasi berbasis katalog.

\section{Estetika dan Desain Minimalis}

Tabel 9

Indikator Estetika dan Desain Minimalis

\begin{tabular}{|l|l|c|}
\hline No. & \multicolumn{1}{|c|}{ Butir Checklist } & ICA-AtoM \\
\hline 1. & Desain aplikasi sistem dibuat minimalis. & V \\
\hline 2. & Kesesuaian perpaduan warna pada template. & V \\
\hline 3. & Pemilihan jenis huruf (font) yang sesuai. & $\mathrm{V}$ \\
\hline & Skor & 3 \\
\hline & Prosentase & $100 \%$ \\
\hline
\end{tabular}

Sumber: Data Primer 
Aspek estetika dalam analisa usability dikatakan cukup tinggi pada software ICAAtoM. Hal tersebut tercantum dalam analisa bahwa dari ke tiga poin indikator aspek estetika dan desain minimalis terpenuhi dengan skor $100 \%$. Secara keseluruhan dikatakan bahwa dalam ICA-AtoM mengenai desain aplikasi yang dibuat cukup minimalis dengan cukup konsistensinya penempatan menu navigator yang disediakan serta template dan font yang disediakan terdapat kesesuaian.

\section{Membantu Pengguna untuk Mengenali, Mendiagnosa, dan Memulihkan dari}

Tabel 10

Indikator Diagnosa dan Pemulihan Kesalahan

\begin{tabular}{|c|c|c|}
\hline No. & $\begin{array}{l}\text { Butir Checklist } \\
\end{array}$ & ICA-AtoM \\
\hline 1. & $\begin{array}{l}\text { Pesan yang ditampilkan saat eror menggunakan bahasa yang } \\
\text { dimengerti. }\end{array}$ & 0 \\
\hline 2. & $\begin{array}{l}\text { Menyediakan feedback (umpan balik) langsung kepada } \\
\text { pengguna dengan instruksi khusus (solusi) ketika terjadi error } \\
\text { (kesalahan). }\end{array}$ & $\mathrm{V}$ \\
\hline \multirow[t]{3}{*}{3.} & $\begin{array}{l}\text { Terdapat menu sebagai reset password ketika terjadi kesalahan } \\
\text { atau pengguna lupa. }\end{array}$ & 0 \\
\hline & Skor & 1 \\
\hline & Prosentase & $33,3 \%$ \\
\hline
\end{tabular}

Sumber: Data Primer

Hasil analisa menunjukkan bahwa dalam hal membantu pengguna untuk mengenali, mendiagnosa, memulihkan dari kesalahan tidak sepenuhnya poin indikator terpenuhi. Prosentase menunjukkan 33,3\% dan hanya satu dari 3 indikator yang memenuhi kriteria. Pertama masalah bahasa yang digunakan ketika terjadi error dapat dikatakan sulit dipahami bagi pengguna khususnya bagi mereka yang awam mengenai bahasa pemrograman ( $s q l, p h p$ dan sebagainya), sebagai contoh pertama adalah pesan error ketika terjadi kegagalan saat proses registrasi saat instalasi keluar error "Fatal error: Call to a member function is Action Cacheable on null in... " hal ini mungkin menjadi mudah bagi mereka yang sudah terbiasa dengan bahasa pemrograman, akan tetapi dilain pihak akan sangat sulit dimengerti oleh pengguna yang masih awam. Kedua masih belum tersedianya fasilitas reset password misalkan dibagian halaman login apabila pengguna lupa dengan kata kunci baik itu username maupun password. 


\section{Bantuan dan Dokumentasi}

Tabel 11

Indikator Bantuan dan Dokumentasi

\begin{tabular}{|l|l|c|}
\hline No. & \multicolumn{1}{|c|}{ Butir Checklist } & ICA-AtoM \\
\hline 1. & Menfasilitasi bantuan kepada pengguna berupa menu (help). & v \\
\hline 2. & $\begin{array}{l}\text { Adanya fitur dokumentasi dalam bentuk teks, video maupun } \\
\text { audio. }\end{array}$ & 0 \\
\hline & Skor & 1 \\
\hline & Prosentase & $50 \%$ \\
\hline
\end{tabular}

Sumber: Data Primer

Analisa usability dalam hal bantuan dan dokumentasi didapatkan hasil prosentase 50\%. Berdasarkan analisis checklist munujukkan bahwa software ICA-AtoM secara garis besar telah memiliki fitur bantuan untuk pengguna berupa menu help yang disediakan, baik dalam halaman dashboard maupun tampilan luar. Namun, dalam hal fitur pelengkap sebagai penjelas informasi seperti fasilitas tutorial berupa dokumentasi dalam berbagai format (teks, video maupun audio) masih belum disediakan oleh sistem.

Berdasar prosentase dari hasil cehcklist tingkat usability software ICA-AtoM secara keseluruhan dapat dilihat hasil rata-rata perolehan prosentase sebagai berikut: 
Tabel 12

Usability Software ICA-ATOM

\begin{tabular}{|l|l|c|}
\hline No. & \multicolumn{1}{|c|}{ Aspek Usability } & Rata-rata \\
\hline 1. & $\begin{array}{l}\text { Visibility of system status (Visibilitas status } \\
\text { system informasi). }\end{array}$ & $33,3 \%$ \\
\hline 2. & $\begin{array}{l}\text { Match between system and the real world } \\
\text { (Kesesuaian antara system dan dunia nyata). }\end{array}$ & $50 \%$ \\
\hline 3. & $\begin{array}{l}\text { User control and freedom (Kontrol dan } \\
\text { Kebebasan Pengguna). }\end{array}$ & $100 \%$ \\
\hline 4. & $\begin{array}{l}\text { Consistency and standards (Standard dan } \\
\text { Konsistensi). }\end{array}$ & $00 \%$ \\
\hline 5. & Error prevention (Pencegahan Kesalahan). \\
\hline 6. & $\begin{array}{l}\text { Recognition rather than recall (Mengenali bukan } \\
\text { Mengingat). }\end{array}$ & $\begin{array}{l}\text { Flexibility and efficiency of use (Fleksibilitas dan } \\
\text { Efisiensi Penggunaan). }\end{array}$ \\
\hline 7. & $\begin{array}{l}\text { Aesthetic and minimalist design (Estetika \& } \\
\text { desain yang minimalis). }\end{array}$ & $100 \%$ \\
\hline 9. & $\begin{array}{l}\text { Help users recognize, diagnose, and recover from } \\
\text { errors } \\
\text { (Membantu pengguna untuk mengenali, } \\
\text { mendiagnosa, memulihkan dari kesalahan). }\end{array}$ & $33,3 \%$ \\
\hline 10. & $\begin{array}{l}\text { Help and documentation (Bantuan dan } \\
\text { dokumentasi). }\end{array}$ & $56 \%$ \\
\hline Jumlah & \\
\hline
\end{tabular}

Sumber: Data Primer

Secara keseluruhan hasil analisis tingkat usability software ICA-AtoM diperoleh hasil perolehan keseluruhan sebesar 56,7\%. Hasil prosentase menunjukkan aspek usability terendah terdapat pada poin error prevention (pencegahan kesalahan) dan recognition rather than recall (mengenali bukan mengingat) di mana masing-masing aspek diperoleh nilai $0 \%$ yang artinya kedua aspek tersebut sama sekali belum terpenuhi. Sedangkan hasil tertinggi diperoleh pada aspek flexibility and efficiency of use (fleksibilitas dan efisiensi enggunaan) dan aesthetic and minimalist design (estetika \& desain yang minimalis) yang masing-masing diperoleh hasil prosentase $100 \%$. 


\section{KESIMPULAN}

Berdasarkan pada hasil analisa tingkat usability software arsip digital berbasis open source ICA-AtoM dapat disimpulkan bahwa masih kurang memenuhi kriteria didalam penilaian usability sebuah sistem. Hal tersebut dapat dilihat dengan berdasar pada hasil prosentase yang diperoleh yaitu hanya sekitar $56,7 \%$. Artinya masih $1 / 2$ dari jumlah total keseluruhan point-point indikator dalam aspek usability yang sudah terpenuhi oleh software ICA-AtoM.

Beberapa aspek usability sangat perlu dikembangkan untuk kemudahan penggunaan oleh pengguna yang antara lain seperti aspek error prevention (pencegahan kesalahan) dan recognition rather than recall (mengenali bukan mengingat). Hal tersebut diperlukan mengingat masih belum terpenuhinya penilaian pada poin usability pada kedua aspek tersebut. Beberapa aspek yang masih kurang yaitu seperti adanya proses loading pada sistem, tanda pengingat guna mengantisipasi terjadinya kesalahan, pengorganisasian informasi sistem yang lebih terstruktur, pilihan bahasa yang lebih beragam khususnya bahasa Indonesia, adanya tombol navigasi yang lebih mudah dipahami, fitur pengecekan atau pembenaran keyword, adanya simbol penuinjukan aplikasi pada sistem, pesan error yang lebih familliar, fitur reset password dan adanya fitur penjelas informasi dalam bentuk media interaktif. 


\section{DAFTAR PUSTAKA}

Alvin Toffler, Alvin. 1980. The Third Wave= gelombang ketiga. Pantja Simpati, Jakarta.

Barthos, Basir. 2005. Manajemen Kearsipan:untuk lembaga negara, swasta dan perguruan tinggi. Bumi Aksara, Jakarta.

Crook, Edgar. 2009. "Web Archiving in a Web 2.0 Word". The Electronic Library. Vol 27 No. 5, 2009, di bawah http://www.emeraldinsight.com/doi/full/10.1108/ 02640470910998542 (diakses 7 Juni, 2017).

Dearstyne, Bruce W. Effective Approaches for Managing Electronic Records and Archives. Oxford: The Scarecrow Press.

Falk, Howard. "Digital Archive

Developments", The Electronic Library, Vol. 21 No. 4 (2003), 375, di bawah http://www.emeraldinsight.com/doi/pdfplus/10.1 108/02640470310491603 (diakses 7 Juni, 2017).

Grahito, Agit. "Pengujian Ketepatan dan Perolehan Aplikasi ICA-AtoM Sebagai Sarana Temu Kembali Arsip: Studi Kasus Arsip Universitas Indonesia (2014), Jurusan Ilmu Perpustakaan FIB Universitas Indonesia, di bawah http://lib.ui.ac.id/naskahringkas/201610//S55383-Agit\%20Grahito (diakses 17 Juni 2017).
Ica-AtoM. The Software: Open Source Archival Description Software. di bawah https://www.ica-atom.org/ diakses 4 Juni 2017.

Jakob Nielsen, Jakob \& Molich. 1994. Enhancing the Explanatory Power of Usability Heuristics. Morristown, New Jersey, USA.

Kemkominfo. "Pengguna Internet di Indonesia Mencapai 82 Juta", di bawah https://kominfo.go.id/index.php/content/detai 1/3980/Kemkominfo\%3A+Pengguna+Interne $\underline{\mathrm{t}+\text { di }+ \text { Indonesia }+ \text { Capai }+82+\text { Juta/0/berita_sat }}$ ker. diakses 2 Juni 2017.

Sipro, Lisa. 2009. Archival Management Software. Council on Library and Information Resources, Washington D.C.

Sugiarto, Agus \& Wahyono, Teguh. 2005. Manajemen Kearsipan Modern: dari konvensional ke basis komputer. Gava Media, Yogyakarta. 